\title{
Pharmacologic Advances in the Treatment of Schizophrenia
}

\author{
Scott A. West, MD \\ University of Cincinnati, Cincinnati Ohio
}

Follow this and additional works at: https://jdc.jefferson.edu/jeffjpsychiatry

Part of the Psychiatry Commons

Let us know how access to this document benefits you

\section{Recommended Citation}

West, MD, Scott A. (1993) "Pharmacologic Advances in the Treatment of Schizophrenia," Jefferson Journal of Psychiatry. Vol. 11 : Iss. 2 , Article 5.

DOI: https://doi.org/10.29046/JJP.011.2.002

Available at: https://jdc.jefferson.edu/jeffjpsychiatry/vol11/iss2/5

This Article is brought to you for free and open access by the Jefferson Digital Commons. The Jefferson Digital Commons is a service of Thomas Jefferson University's Center for Teaching and Learning (CTL). The Commons is a showcase for Jefferson books and journals, peer-reviewed scholarly publications, unique historical collections from the University archives, and teaching tools. The Jefferson Digital Commons allows researchers and interested readers anywhere in the world to learn about and keep up to date with Jefferson scholarship. This article has been accepted for inclusion in Jefferson Journal of Psychiatry by an authorized administrator of the Jefferson Digital Commons. For more information, please contact: JeffersonDigitalCommons@jefferson.edu. 


\title{
Pharmacologic Advances in the Treatment of Schizophrenia
}

\author{
Scott A. West, M.D.
}

\begin{abstract}
The treatment of schizophrenia was rewolutionized with the introduction of chlorpromazine in 1952. The effectiveness of chlorpromazine in controlling psychotic symptoms lead to the dopamine hypothesis of schizophrenia, which revolutionized our conceptualization of this illness. Since that time, numerous typical antipsychotic drugs have been developed for the treatment of schizophrenia. However, the introduction of clozapine in 1990 began a new era in the pharmacologic management of schizophrenia. Clozapine, an atypical antipsychotic drug, is effective in controlling the positive symptoms of schizophrenia in a large number of otherwise treatment-resistant patients, and also improves the negative symptoms of the illness in many patients. Clozapine is classified as an atypical antipsychotic drug because it has little potential for causing extrapyramidal side effects, and its effects on dopaminergic and serotonergic neurotransmitter systems are unique compared with those of typical antipsychotic medications. The effectiveness of clozapine and the explosion of research in neuroscience has led to the investigation of neurotransmitter systems other than dopamine as important in developing pharmacologic strategies for the treatment of schizophrenia. This paper will review current pharmacologic advances in the treatment of schizophrenia, and highlight the clinical findings and use of clozapine, the prototype of a new generation of antipsychotic drugs.
\end{abstract}

\section{INTRODUCTION}

Schizophrenia was classified as a syndrome almost 100 years ago, and while this illness was well characterized by Kraepelin, Bleuler and others, adequate treatment for this disorder did not become available until the 1950's. Earlier treatments included hydrotherapy, insulin shock therapy, electroconvulsive therapy, and frontal lobotomy. However in 1952, with the introduction of chlorpromazine, the treatment approach to schizophrenia was radically changed. For the first time, a medication was available that was effective in controlling psychotic symptoms in a large number of patients. Patients improved enough to benefit from other therapies, including supportive and group psychotherapy, recreational therapy and occupational therapy. These modalities could now be used effectively to provide long-term psychosocial rehabilitation in order to improve the quality of life of patients with schizophrenia.

The well known pharmacologic effect of dopamine (DA) blockade by chlorpromazine lead to the dopamine hypothesis of schizophrenia which truly revolutionized our

Scott A. West, M.D. is a Fellow in the Biological Psychiatry Program at the University of Cincinnati College of Medicine. 
conceptualization of this illness, and served as a major impetus to intensely scrutinize the neurochemistry of the disorder $(1,2)$. Subsequent to the introduction of chlorpromazine, numerous other dopamine blocking agents, initially called "neuroleptics" because they have the inherent risk of producing extrapyramidal neurological side effects, have become available for the treatment of schizophrenia. The introduction of clozapine began a new era in the pharmacologic management of schizophrenia. Clozapine became the first true "atypical" antipsychotic medication available for clinical use. Antipsychotics classified as "atypical" generally include the following characteristics: they (1) do not cause catalepsy in animal models, (2) cause minimal or no extrapyramidal symptoms (EPS) in humans, (3) have little effect on plasma prolactin concentrations (typical antipsychotics increase plasma prolactin), (4) have greater $5-\mathrm{HT}_{2}$ receptor blockade than typical antipsychotic medications, (5) tend to have more $\mathrm{D}_{1}$ receptor blockade than typical antipsychotics. Thus, atypical antipsychotics such as clozapine have minimal or no liability for producing movement disorders, a tremendous advantage considering approximately 15-20 percent of all patients on long-term antipsychotic drugs develop tardive dyskinesia, and another 1 percent develop tardive dystonia (3-5).

The recent explosion of research in neuroscience and the effectiveness of the atypical antipsychotics has led to the investigation of neurotransmitter systems other than dopamine as important pharmacological strategies for the treatment of schizophrenia. Other systems under investigation that have been implicated in the pathophysiology of schizophrenia include serotonin (5-HT), $\sigma$-opioid, neurotensin (NT), and N-methyl-D-aspartate (NMDA).

This paper will review the pharmacological strategies used in the development of new antipsychotic drugs, as the pathophysiology of schizophrenia becomes further elucidated. Numerous medications, including many atypical antipsychotic drugs, are at various stages in clinical trials, and some will become available for clinical use in the near future. Since clozapine is currently the only atypical antipsychotic drug available for use, it will be addressed in detail.

\section{Pharmacological Strategies}

The dopaminergic system has traditionally been the primary focus of many investigational drugs due to the efficacy of $\mathrm{D}_{2}$ antagonists in controlling the positive symptoms (eg. hallucinations, delusions) of schizophrenia (1,2). Drugs that are selective $\mathrm{D}_{2}$ antagonists have proven to be clinically useful, yet the potential for the development of EPS and tardive dyskinesia remains relatively high, which is a major disadvantage. Drugs in this class include the benzamides sulpiride (the prototype), raclopride and remoxipride; studies have demonstrated that the latter two medications are efficacious and well-tolerated, and they may receive FDA approval soon (6).

Terguride is a partial $\mathrm{D}_{2}$ agonist that may be effective in alleviating both positive and negative symptoms (eg. blunted affect, social isolation) of schizophrenia (7). Partial $\mathrm{D}_{2}$ agonists are capable of up or down regulating different dopaminergic pathways by increasing or decreasing neurotransmission in hypo- or hyper- 
functioning pathways, respectively. The hypothesis that there is a reduction of synaptic DA in the frontal cortex which results in the negative symptoms and an increase in synaptic DA in the mesolimbic system resulting in positive symptoms has led to the use of partial agonists to modulate these circuits.

The identification of multiple subtypes of DA receptors has led to the development of other hypotheses in addition to $\mathrm{D}_{2}$ dysregulation. Preferential $\mathrm{D}_{1}$ antagonism $\left(D_{1}>D_{2}\right)$ seems to play an important role in the treatment of many schizophrenic patients $(7,8)$. Several drugs have recently been identified that are much more selective for $\mathrm{D}_{1}$ receptors, without strong cholinergic, serotonergic, and noradrenergic activity (7). Preferential $D_{1}$ antagonists appear to have very little potential for producing EPS, which may imply that the ratio of $D_{1}: D_{2}$ blockade is an important factor in the development of EPS.

There are several serotonin-based strategies, and 5- $\mathrm{HT}_{2}$ antagonists seem to be particularly promising $(6,7,9)$. It has been postulated that blockade of $5-\mathrm{HT}_{2}$ receptors is the mechanism responsible for the success of clozapine in improving the negative symptoms of schizophrenia. Other drugs with significant $5-\mathrm{HT}_{2}$ blockade include fluperlapine, sertindole, olanzapine, and risperidone, which has recently been filed with the FDA and is awaiting approval. Additionally, 5- $\mathrm{HT}_{3}$ antagonists and $5-\mathrm{HT}_{\mathrm{la}}$ agonists are also under investigation; however, the antipsychotic efficacy of these agents is not well established.

The role of $\sigma$-opioid receptors in the pathophysiology of schizophrenia is also under investigation $(7,10)$. This approach is based on evidence that typical antipsychotic drugs, such as haloperidol, have an affinity to the $\sigma$-opioid receptor, and it has been postulated that this may contribute to the antipsychotic efficacy of these medications. It has also been demonstrated that remoxipride has an affinity to the $\sigma$-opioid receptor. The $\sigma$-opioid antagonist rimcazole has been disappointing however, due to both its lack of efficacy and an unfavorable side effect profile, including a relatively high incidence of seizures (7).

Neurotensin (NT), an endogenous tridecapeptide, possesses many pharmacological properties in common with atypical antipsychotics (11). It has been demonstrated that both typical and atypical antipsychotic drugs increase NT concentrations in the nucleus accumbens, and typical antipsychotics increase NT concentrations in the caudate nucleus as well (12-14). The development of NT agonists will allow its role in the pathophysiology of schizophrenia to be further elucidated.

NMDA agonism may provide yet another promising approach to the development of atypical antipsychotic drugs. The phencyclidine (PCP)/NMDA model of schizophrenia hypothesizes that there is a relative decrease in glutamatergic neurotransmission due to inhibition of the NMDA type of glutamate receptor $(15,16)$. This model was originally proposed after numerous patients with PCP intoxication presented with a clinical picture indistinguishable from schizophrenia, including the presence of both positive and negative symptoms (16). Therefore, NMDA agonists capable of increasing glutamatergic/NMDA neurotransmission may prove to be very useful. Medications developed thus far have been intolerable for patients, and currently there are no drugs in clinical use. However, the addition of the amino acid 
glycine, a co-agonist at the NMDA receptor complex, to typical antipsychotic medications has proven to be a useful adjuvant for some patients $(17,18)$.

\section{Clozapine}

Clozapine was developed over thirty years ago, and has been used extensively in Europe since the 1960's. Shortly after the study published by Shopsin et al (1979), clozapine was banned from further investigation in the United States due to a number of fatal cases of agranulocytosis associated with its use (19). However, clozapine was reintroduced into the United States several years later, and the hallmark study by Kane et al (1988), demonstrating its efficacy in treatmentresistant schizophrenic patients, led to its eventual approval by the FDA in 1990. The approval had the stipulation that weekly white blood counts (WBCs) would be monitored in patients in order to detect the rare occurance of agranulocytosis (20). Clozapine is currently indicated for use in patients who are treatment-resistant, loosely defined as those who have failed trials of several different typical antipsychotic drugs, or in patients who are unable to tolerate typical antipsychotic drugs due to severe side effects, including tardive dyskinesia.

\section{Pharmacology}

Clozapine is a dibenzodiazepine that is chemically related to the typical antipsychotic loxapine (21). Clozapine is not a selective DA antagonist; in fact it has greater affinity for cholinergic (muscarinic), serotonergic, noradrenergic $\left(\alpha_{1}\right.$ and $\alpha_{2}$ ), and histaminergic $\left(\mathrm{H}_{1}\right)$ receptors than for dopaminergic receptors $(22-25)$. While the precise mechanism of action is unknown, many authors have postulated that the $5-\mathrm{HT}_{2}$ antagonism of clozapine accounts (at least in part) for its efficacy, especially with regard to improvements in negative symptoms commonly observed in patients (6). Blockade of the noradrenergic, histaminergic and cholinergic receptors, while not thought to be responsible for any therapeutic actions of clozapine, are responsible for many of the drugs side effects.

Clozapine, unlike typical antipsychotics, binds preferentially to DA receptors in the mesocortical and mesolimbic regions of the brain (26). In addition, clozapine has a relatively greater affinity for the $\mathrm{D}_{1}$ receptor compared with the $\mathrm{D}_{2}$ receptor (26). These properties may explain why clozapine has a very low incidence of EPS. Farde et al (1992) demonstrated with positron emission tomography that $\mathrm{D}_{2}$ receptor occupancy in the basal ganglia of patients treated with clozapine was $38 \%$ to $63 \%$, significantly lower than the $70 \%$ to $89 \%$ that was found in patients on typical antipsychotics, indicating less nigrostriatal blockade in patients on clozapine (27). Further evidence supporting the relative selectivity of clozapine for discrete dopaminergic pathways is that its effects on the tuberoinfundibular system is minimal and transient. This is based on evidence that plasma prolactin concentrations are not elevated in patients on clozapine therapy, except for an initial marginal increase that is occasionally observed which rapidly returns to baseline with continued treatment 
$(28,29)$. This is in contrast to typical antipsychotics, which elevate plasma prolactin concentrations throughout therapy (30).

\section{Pharmacokinetics}

The bioavailability of clozapine varies markedly among published reports, but averages 50 to 60 percent of the oral dose, and most of the drug is protein bound (21). Peak plasma concentrations are attained about 2 hours after ingestion, and side effects, especially orthostatic hypotension, typically peak at this time (21). The metabolism of clozapine is complex, as it undergoes multiple oxidation reactions and demethylation in the liver, resulting in $80 \%$ of the drug being excreted as metabolites $(31,32)$. The half-life elimination of clozapine is 12 to 16 hours, which allows for convenient twice-a-day dosing. Plasma drug levels in the range of 200 to $400 \mathrm{ng} / \mathrm{ml}$ are common in patients on a typical dose of 300 to $500 \mathrm{mg} /$ day (21). Initially, plasma drug concentrations did not seem to correlate well with drug response; however, more recent data indicates that the majority of patients who respond to clozapine have drug levels of $350 \mathrm{ng} / \mathrm{ml}$ or greater (Meltzer, unpublished data). Furthermore, nonresponders with blood levels below $350 \mathrm{ng} / \mathrm{ml}$ have converted to responders by increasing the dose of clozapine to achieve this minimum plasma concentration. Therefore, in at least a subpopulation of patients, plasma drug concentrations correlate well with clinical response to clozapine.

\section{Clinical Response}

There have been numerous controlled trials comparing the efficacy of typical antipsychotics with clozapine. Shopsin et al (1979) conducted a double-blind comparison of clozapine and chlorpromazine in the treatment of acutely psychotic schizophrenic patients and found clozapine was equal or superior to chlorpromazine in controlling psychotic symptoms (19).

However, it was the hallmark, multicenter study by Kane et al (1988) that clearly established the efficacy of clozapine in treatment-resistant schizophrenic patients (20). This study included patients who met DSM-III criteria for schizophrenia and who had previously failed to respond to at least 3 different typical antipsychotic drugs. Patients initially underwent a prospective, single-blind trial of haloperidol (mean dosage $61 \mathrm{mg} /$ day) for six weeks. Eighty percent (268) of the patients failed to respond, and were randomized in a double-blind manner to treatment with either clozapine (up to $900 \mathrm{mg} /$ day) or chlorpromazine (up to $1800 \mathrm{mg} /$ day). After six weeks, $30 \%$ of patients in the clozapine-treated group were classified as responders compared with $4 \%$ in the chlorpromazine-treated group. It was also noted that negative, as well as positive, symptoms improved in patients who received clozapine.

In a recent study by Pickar et al (1992), 21 patients with schizophrenia who were either treatment-resistant or unable to tolerate typical antipsychotic medications were enrolled in a crossover, placebo-controlled, double-blind comparison trial of clozapine and fluphenazine (33). Thirty-eight percent $(n=8)$ of the patients demon- 
strated greater improvement with clozapine, and clozapine significantly reduced both positive and negative symptoms compared with fluphenazine and placebo. No improvement in negative symptoms was observed with fluphenazine treatment or placebo. It was also found that low ratios of cerebrospinal fluid homovanillic acid (a metabolite of DA) to 5-hydroxyindoleacetic acid (a metabolite of serotonin) predicted clozapine superiority, suggesting that an imbalance. between these two systems may be responsible for producing some symptoms of schizophrenia, and that the dual action of clozapine on both DA and 5-HT systems corrects this imbalance. In addition, patients who experienced significant EPS with fluphenazine treatment had a more favorable response to clozapine.

\section{Clinical Use}

Clozapine is currently available as scored $25 \mathrm{mg}$ and unscored $100 \mathrm{mg}$ tablets. Patients are typically started on $25 \mathrm{mg}$ twice-daily, but elderly patients may need to begin with $12.5 \mathrm{mg}$ daily. The dose is titrated upward by 25 to $50 \mathrm{mg}$ every day (or in $12.5 \mathrm{mg}$ increments in the elderly) as tolerated. Rapid upward titration may be limited by adverse effects, most notably orthostatic hypotension and sedation. If patients are initiated on clozapine therapy on an outpatient basis, less aggressive titration is recommended since patients cannot be closely monitored. Although there is a wide range of reported effective daily doses (from 25 to $900 \mathrm{mg}$ ), a dose of 300 to $500 \mathrm{mg}$ per day has been shown to be the effective dose range for the majority of schizophrenic patients (21).

What constitutes an adequate trial of clozapine is still being determined, but it is clear that many patients may not show any significant improvement until 3 to 6 months into therapy (Meltzer, unpublished data). Furthermore, many patients demonstrate continual improvement after 6 to 12 months of clozapine treatment (6). This seems to be a unique feature of clozapine, and emphasizes the importance of a long-term trial before the drug is discontinued in a patient due to presumed lack of efficacy.

Clozapine treatment should not be initiated in patients with a history of a myeloproliferative disorder, previous clozapine-induced granulocytopenia or agranulocytosis, or a WBC of less than $3500 / \mathrm{mm}^{3}$. A relative contraindication to treatment with clozapine includes concurrent use of other medications with the potential for bone marrow suppression (ie. carbamazepine). Additionally, the coadministration of clozapine with benzodiazepines should be done with caution because of several reports of sudden death in patients on clozapine who have also received a benzodiazepine $(34,35)$. At this time, however, there is no absolute contraindication to the concurrent use of benzodiazepines with clozapine.

\section{Adverse Effects}

Agranulocytosis is the primary concern with the use of clozapine; and the extent to which patients are monitored highlights the concern over this generally reversible 
but potentially fatal adverse event $(21,36)$. Weekly WBCs are mandatory in all patients on clozapine, which allows for the early detection of leukopenia or granulocytopenia, should it occur. However, it should be noted that fluctuations in white blood counts are common in patients on clozapine, but any downward trend in counts should be closely scrutinized. The incidence of agranulocytosis is about 0.6 percent, and leukopenia 1.8 percent (21). The mechanism of agranulocytosis is unknown and it does not appear to be dose-related. The vast majority of cases have occured within the first 6 months of therapy, but there have been isolated reports of agranulocytosis occuring in patients after 15 months of treatment. Recovery generally occurs within three weeks following discontinuation of clozapine (22).

Clozapine, like typical antipsychotic drugs, lowers the seizure threshold and may precipitate seizures. Unlike agranulocytosis, this is clearly a dose-related phenomenon, with the incidence ranging from 0.6 percent in patients on less than $300 \mathrm{mg}$ per day, to 14 percent in patients taking over $600 \mathrm{mg}$ per day (22). In addition to the absolute dose of clozapine, the rate of titration is also a major factor affecting the incidence of seizures. In patients at high risk or who are on more than $600 \mathrm{mg}$ of clozapine a day, prophlaxis with an anticonvulsant, such as valproic acid, should be considered. If a seizure does occur, the medication may be reinstituted at half the previous dose after an anticonvulsant is added.

There are numerous other adverse effects due to the antagonistic properties of clozapine at histaminergic, noradrenergic and cholinergic receptors. The incidence of these effects varies among published reports, but they include: sedation, tachycardia, orthostatic hypotension, constipation, dizziness, sialorrhea (paradoxical, considering clozapine is a potent muscarinic antagonist), hyperthermia and weight gain, among others. While these side effects may be bothersome, they rarely necessitate stopping the medication, generally improve with continued treatment, can sometimes be managed with adjunctive medications, and may be minimized with slow titration of the drug.

\section{CONCLUSION}

The treatment of schizophrenia has been greatly enhanced by the recent explosion of research in neuroscience. The belief that schizophrenia is purely an illness of DA hyperactivity is no longer universally accepted. Clearly some symptoms may be explained by DA hyperactivity, but others appear to be secondary to hypoactive DA circuits. Thus, the belief that $\mathrm{D}_{2}$ blockade is the most important factor in the treatment of schizophrenia is also losing widespread support. Although $\mathrm{D}_{2}$ blockade still seems to play a major role in the treatment of positive symptoms, there is sufficient data to support a role for $\mathrm{D}_{1}$ receptor blockade as well. The concept of negative symptoms and the success of drugs that are $5-\mathrm{HT}_{2}$ antagonists in the treatment of these symptoms is the strongest evidence to date supporting a putative neurotransmitter abnormality other than DA in schizophrenia. Furthermore, the concept of "neurotransmitter balance," which emphasizes the interaction between different neurotransmitter systems, as being important for normal brain function 
and altered in patients with schizophrenia is gaining widespread acceptance among leading researchers in the field. Thus, like clozapine, newer medications for the treatment of schizophrenia will not be pure $\mathrm{D}_{2}$ antagonists. To the contrary, newer antipsychotics will have less $\mathrm{D}_{2}$ blockade, more $\mathrm{D}_{1}$ and $5-\mathrm{HT}_{2}$ blockade, and hopefully less adrenergic, cholinergic, and histaminergic blockade.

In review, numerous nondopaminergic systems have been implicated in the pathophysiology of schizophrenia, including those that utilize the neurotransmitters serotonin, $\sigma$-opioid, neurotensin, and N-methyl-D-aspartate. This has led to the development of a new generation of drugs for the treatment of this major psychiatric illness. Clozapine is the first atypical antipsychotic that has proven to be effective in schizophrenia, even in those patients who are otherwise treatment-resistant to typical antipsychotic drugs. Furthermore, clozapine improves negative, as well as positive, symptoms of schizophrenia, and has little potential for inducing movement disorders.

\section{REFERENCES}

1. Davis KL, Kahn RS, Ko G, Davidson M: Dopamine in schizophrenia: a review and reconceptualization. Am J Psychiatry 1991; 148:1474-1486

2. Sayed Y, Garrison JM: The dopamine hypothesis of schizophrenia and the antagonistic action of neuroleptic drugs-a review. Psychopharmacol Bull 1983; 19:283-288

3. Woerner MG, Kane JM, Lieberman JA, et al: The prevalence of tardive dyskinesia. J Clin Psychopharmacol 1991; 11:34-42

4. Khot V, Wyatt RJ: Not all that moves is tardive dyskinesia. Am J Psychiatry 1991; 148:661-666

5. Sachdev P: Clinical characteristics of 15 patients with tardive dystonia. Am J Psychiatry 1993; 150:498-500

6. Owens MJ, Risch SC: Atypical antipsychotics. In: APA Textbook of Psychoharmacology, edited by Nemeroff CB and Schatzberg AF, APA Press, Washington, DC, (in press)

7. Coward DM: Pharmacological approaches to the development of atypical antipsychotics. In: Advances in Neuropsychiatry and Psychopharmacology, Volume 1: Schizophrenia Research, edited by Tamminga CA and Schultz SC, Raven Press, Ltd, New York, 1991, pp 297-305

8. Farde L, Wiesel F-A, Halldin C, Sedvall G: Central $\mathrm{D}_{2}$ receptor occupancy in schizophrenic patients treated with antipsychotic drugs. Arch Gen Psychiatry 1988; 45:71-76

9. Meltzer HY: Dopaminergic and serotonergic mechanisms in the action of clozapine. In: Advances in Neuropsychiatry and Psychopharmacology, Volume 1: Schizophrenia Research, edited by Tamminga CA and Schultz SC, Raven Press, Ltd, New York, 1991, pp 333-340

10. Deutsch SI, Weizman A, Goldman ME, Morihisa JM: The sigma receptor: a novel sight implicated in psychosis and antipsychotic drug efficacy. Clin Neuropharmacol 1988; 11:105-119

11. Levant B, Nemeroff CB: The psychobiology of neurotensin. In: Current Topics of Neuroendocrinology, edited by Ganten D and Pfaff D, 1988, pp 231-262

12. Kilts CD, Anderson CM, Bissette G, et al: Differential effects of antipsychotic drugs on the neurotensin content of discrete brain nuclei. Biochem Pharmacol 1988; 37:1547-1554 
13. Levant B, Nemeroff CB: Sigma receptor antagonist BMY 14802 increases neurotensin concentrations in the rat nucleus accumbens and caudate. J Pharmacol Exp Ther 1990; 254:330-335

14. Levant B, Bissette G, Davis D, et al: Effects of CI-943, a potential antipsychotic drug, and haloperidol on regional brain neurotensin concentrations. Synapse 1991; 9:225-230

15. Javitt DC, Zukin SR: Recent advances in the phencyclidine model of schizophrenia. Am J Psychiatry 1991; 148:1301-1308

16. Heresco-Levy U, Javitt DC, Zukin SR: The phencyclindine/N-methyl-D-aspartate (PCP/ NMDA) model of schizophrenia: theoretical and clinical implications. Psychiatric Annals 1993; 23:135-143

17. Costa J, Khaled E, Sramek J, et al: An open trial of glycine as an adjunct to neuroleptics in chronic treatment-resistant schizophrenics. J Clin Psychopharmacol 1989; 9:6

18. Rosse BR, Thent SK, Banay-Schwartz M, et al: Glycine adjuvant therapy to conventional neuroleptic treatment in schizophrenia: an open label, pilot study. Clin Neuropharmacol $1989 ; 12: 416-424$

19. Shopsin B, Klein H, Aaronsom M, Collora M: Clozapine, chlorpromazine, and placebo in newly hospitalized, acutely schizophrenic patients: a controlled, double-blind comparison. Arch Gen Psychiatry 1979; 36:657-664

20. Kane J, Honigfeld G, Singer J, Meltzer H: Clozapine for the treatment-resistant schizophrenic: a double-blind comparison with chlorpromazine. Arch Gen Psychiatry 1988; 45:789-796

21. Baldessarini RJ, Frankenburg FR: Clozapine: a novel antipsychotic agent. New Engl J Med 1991; 324:746-754

22. Lieberman JA, Kane JM, Johns CA: Clozapine: guidelines for clinical management. J Clin Psychiatry $1989 ; 50: 329-338$

23. Richelson E: Neuroleptics and neurotransmitter receptors. Psychiatric Annals 1980; 10:21-26

24. Richelson E: Neuroleptic affinities for human brain receptors and there use in predicting adverse effects. J Clin Psychiatry 1984; 45:331-336

25. Hyttel J, Larsen JJ, Christensen AV, et al: Receptor-binding profiles of neuroleptics. In: Dyskinesia: Research and Treatment, edited by Casey DE, Springer-Verlag, New York, 1985, pp 9-18

26. Chiodo LA, Bunney BS: Typical and atypical neuroleptics: differential effects of chronic administration on the activity of A9 and A10 midbrain dopaminergic neurons. J Neuroscience 1983; 3:1607-1619

27. Farde L, Nordstrom A-L, Wiesel F-A, et al: Positron emission tomographic analysis of central $D_{1}$ and $D_{2}$ dopamine receptor occupancy in patients treated with classical neuroleptics and clozapine. Arch Gen Psychiatry 1992; 49:538-544

28. Meltzer HY, Goode DJ, Schyve PM, et al: Effect of clozapine on human serum prolactin levels. Am J Psychiatry 1979; 136:1550-1555

29. Kane JM, Cooper TB, Sachar EJ, et al: Clozapine: plasma levels and prolactin response. Psychopharmacology 1981; 73:184-187

30. Langer G, Sachar EJ, Halpern FS, et al: The prolactin response to neuroleptic drugs. A test of dopaminergic blockade: neuroendocrine studies in normal men. J Clin Endocrinol Metab 1977; 45:996-1002

31. Bailey P, Barnes P, Rosengren-Keith B, et al: Clozaril products claims and evidence. Ware, England: B Ward, 1990, pp 1-72 
32. Choc MG, Lehr RG, Hsuan F, et al: Multiple-dose pharmacokinetics of clozapine in patients. Pharm Res 1987; 4:402-405

33. Pickar D, Owen R, Litman R, et al: Clinical and biological response to clozapine in patients with schizophrenia: crossover comparison with fluphenazine. Arch Gen Psychiatry 1992; 49:345-353

34. Grohmann R, et al: Adverse effects of clozapine. Psychopharmacol 1989; 99(suppl):S101S104

35. Sassim N, Grohmann R: Adverse drug reactions with clozapine and simultaneous application of benzodiazepines. Pharmacopsychiatry 1988; 21:306-307

36. Lieberman JA, Johns CA, Kane JM, et al: Clozapine-induced agranulocytosis: non-crossreactivity with other psychotropic drugs. J Clin Psychiatry 1988; 49:271-277 